\section{MISSION HOSPITAL, KASHMIR.}

A CASE OF RENAL IRRITATION SIMULATING CALCULCS OF THE KIDNEY CURED BY NEPHROTOMY.

(Under the care of Dr. ERNEST F. NEvE.)

Most surgeons of experience have met with cases in which renal pain was thought to be due to calculus, where subsequent operation has relieved the symptoms for which treatment was sought, but has not shown the presence of a stone. In some instances no stone has been found, although it was present, in consequence of imperfect search; the stone has been small and placed in the substance of the kidney, or it has been fixed in a deeply lying calyx. Careful and systematic search is required, but we have seen a small calculus escape detection altogether by skilled hands until the kidney was fully incised after nephrectomy. Mr. Greig Smith ${ }^{1}$ puts the proportion of failures to find a stone as onefifth of the operations undertaken for the purpose of nephrolithotomy. Mr. Jacobson ${ }^{2}$ gives the following list of the chief conditions which simulate renal calculus : (1) lithiasis ; (2) tuberculous kidney; (3) slight pyelitis ; (4) moveable kidney; (5) aching kidney; (6) nephralgias due to disease in parts adjacent to the kidney; (7) gall-stones retained in the gall-bladder ; (8) spinal disease ; (9) interstitial shrinking nephritis; and (10) new growth of kidney in its early stage. It is, however, only necessary to mention most of these to prevent anyone exercising ordinary care, from making a mistake in diagnosis.

A native, aged forty years, had complained for three years of periodical attacks of severe renal pain. His general condition was good. The urine was loaded with oxalate crystals and showed traces of pus. There was distinct but slight tenderness on pressure over the right kidney. On Oct. 7th, 1895, I made an incision four inches long almost horizontally backward from the tip of the last rib. Displacing the ascending colon and peritoneum forwards, the kidney was found after some searching, and was exposed by scraping through the fat with the finger. No stone could be detected on palpation. There was a little doubt as to whether, on needling, a slightly gritty-feeling area was traversed. On incising the pelvis and sounding systematically there was no sign of stone. The renal wound was stitched, also that in the loin, a drainage-tube of small calibre being left in. This was gradually shortened, and finally removed on the twenty-second day. The patient was dismissed on May 1st, 1896, free from pain, having had no return of his old symptoms.

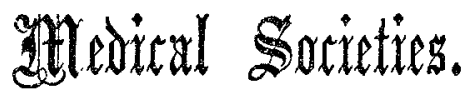

\section{ROYAL MEDICAL AND CHIRURGICAL SOCIETY.}

\section{Annual Meeting.}

THE annual general meeting of this society was held on March 1st, the President, Dr. Howship Dickrnson, being in the chair.

The report of the Council was read. The report showed the flourishing state of the society, a record number of fortyeight Fellows having been elected during the year. The death roll had also been unusually heavy, twenty.five Fellows having died during the twelve months. The arrangements for converting the original 4 per cent. debenture loan into 3 per cent debentures had been satisfactorily accomplisbed, and would result in a saving to the society of about $£ 350$ per annum. - After some remarks by Mr. T. HoLMLEs and Dr. THEODORE WILLIAIIS the report was adopted.

The PRESIDENT, in his annual address, referred with satisfaction to the success of the conversion of the loan. The dinner at the Hotel Cecil, which is a new departare, had been a success, and he hoped that it would become an annual institution. The customary obituary notices of deceased Fellows closed the address, special reference being made to the lives of Professor Du Bois

$$
\text { I Abdominal Surgery, vol. ii }
$$

2 Jacobson: The Operations of Surgery, second edition, p. 705.
Reymond, Sir J. Russell Reynolds, Sir George Humphry, Sir George Johnson, and Mr. George D. Pollock.

After the usual votes of thanks had been passed the officers and council were elected to serve during the ensuing year. The following list was chosen : President : William Howship Dickinson, M.D. Vice-Presidents: William Marcet, M.D., F.R.S.; James Edward Pollock, M.D.; Frederick James Gant; and Charles Sissmore Tomes, F.R S. Honorary treasurers: William Selby Church, M.D., and J. Warrington Haward. Honorary secretaries: Norman Moore, M.D., and Robert William Parker. Honorary librarians : Samuel Jones Gee, M.D., and Rickman J. Godlee, M S. Members of Council : John Abercrombie, $M$ D.; Robert Leamon Bowles, M D.; John Mitchell Bruce, M.D.; David Ferrier, M.D., F.R S.; Joseph Arderne Ormerod, M.D.; William Watson Cheyne, F.R.S. ; Henry Hugh Clutton; Frederick S. Eve; William Appleton Meredith; and Robert Alexander Gibbons, M.D.

\section{PATHOLOGICAL SOCIETY OF LONDON,}

\section{Exhibition of Cases and Specimens.-Epithelioma of the} Penis.-Changes in the Sub.maxillary ciland Secondary to Cancer of the Mouth.

A MeEting of this society was held on March 2nd, Mr. ButLIN, the President, being in the chair.

Dr. F. J. SMITH and Mr. J. H. TARGent showed a case of Aneurysm of the Aorta in a boy eight years of age. There was practically no history, the boy having been suddenly seized with dyspncea only a few hours before his death, which occurred almost immediately after his admission to hospital. Post mortem a sacculated aneurysm the size of an orange was found projecting backwards from the upper part of the descending arch of the aorta and pressing on the cesophagus. The heart and cesophagus were perfectly free from disease, and to the naked eye the inner coat of the aorta was not degenerated. There was, however, a stenosis of the aorta, apparently congenital, just beyond the origin of the left subclavian artery; but as this was on the cardiac side of the aneurysm it was not easy to see what part the stricture could have played in the formation of the aneurysm.-At the suggestion of the PRESIDENT the specimen was referred to the morbid growths committee.

Dr. CYRIL OGLE showed a specimen of Dermoid Growth with Invasion of the Lung. The specimen was removed from the body of a man, twenty-eight years of age, who died from profuse hæmoptysis. He had suffered intermittently from cough and hæmoptysis for five years. On admission the temperature was hectic and the expectoration fotid, the physical signs suggesting empyema. At the necropsy a cavity about four inches in diameter was found in the lower lobe of the right lung, which communicated freely with the middle primary division of the bronchus. It contained: (1) offensive grumons pus; (2) cheesy material, evidently sebaceous; and (3) five or six cream.coloured bodies like swollen digits, flabby, and covered with skin and fine hairs. Their attached ends were fused together into a firm mass which could be traced through the wall of the cyst, and was continuous with a mass which reached forward into the anterior mediastinum. Embedded in the central core was a large tooth. A microscopic section of one of the tongueiike processes showed a covering of stratified epithelium over a stroma of fibrous tissue containing come fat cells. There was evidence of inflammation near the surface only.Mr. GODLEE said that these rare tumours did not appear to give rise to symptoms till adult life, and that then the symptoms were often those of empyema, and a purulent effusion did occur. In a case be had observed the symptoms began acutely in adult life, with expectoration of pus containing a few hairs. A few years later an incision was made into the cavity, which contained the same finger-like processes and some long hairs. The cyst was lined by a membrane exactly similar to that covering the digitations. In another case the symptoms commenced suddenly with a pleural effusion, at first serous and afterwards bloody. Later a tumour formed at the ensiform cartilage, and an incision liberated thick brown pus and greasy matter, possibly sebaceous. The wound ultimately healed, but later a fresh sinus formed near the clavicle and discharged for some time, but at length closed.

Mr. Hutchunsoy and Mr. E. Frazer read a paper, with lantern demonstration, on Epithelioma of the P'enis. They 